\title{
Information Arts and Information Science: Time to Unite?
}

\author{
Murat Karamuftuoglu \\ Department of Communication and Design, Bilkent University, Bilkent, 06800 Ankara, Turkey. \\ E-mail: hmk@bilkent.edu.tr
}

\begin{abstract}
This article explicates the common ground between two currently independent fields of inquiry, namely information arts and information science, and suggests a framework that could unite them as a single field of study. The article defines and clarifies the meaning of information art and presents an axiological framework that could be used to judge the value of works of information art. The axiological framework is applied to examples of works of information art to demonstrate its use. The article argues that both information arts and information science could be studied under a common framework; namely, the domain-analytic or sociocognitive approach. It also is argued that the unification of the two fields could help enhance the meaning and scope of both information science and information arts and therefore be beneficial to both fields.
\end{abstract}

\section{Introduction}

Information arts and information science are, at present, two independent fields of practice which share a common label. There is little, if any, communication between concepts, methods, theories, and research interests of the two fields. Information scientists generally are not aware of the emerging field of information arts, and conversely, artists who produce works of information art are not familiar with the body of work developed in information science. This article aims to show that the two fields in fact share more than a name and that knowledge produced in either field could enhance and help develop the other. In fact, it is the objective of this article to demonstrate that the two fields could be studied under a single framework or theoretical approach. In particular, it will be demonstrated that certain approaches that have been developed to analyze documents and documentary retrieval systems in the recent years also could be used to analyze works of information art. This, in turn, has certain implications for the definition and scope of information science, which also is addressed in the article. In short, it is the argument of the article that unification of

Received September 1, 2005; revised November 9, 2005; accepted November 9, 2005

(C) 2006 Wiley Periodicals, Inc. • Published online 12 September 2006 in Wiley InterScience (www.interscience.wiley.com). DOI: 10.1002/asi.20381 information arts and science is possible and desirable for both fields.

In the rest of the present section, the term information arts is discussed and its various meanings identified. The next section discusses the changing functions of art and roles of artists, and presents an axiological framework that outlines how value of works of information art could be judged. The use of the axiological framework is illustrated by a number of real and fictitious works of art. It also is argued that information science and information arts could be united under a common framework; namely, the domainanalytic approach put forward by Birger Hjørland and colleagues (Hjørland, 1992, 1997a; Hjørland \& Albrechtsen, 1995). The penultimate section discusses further the parallels between the two fields and argues that information artists could be trained in similar ways to information scientists. The final section presents the main conclusions that can be drawn from the article.

\section{Early Conceptual Information Arts}

Whereas information science as a discipline has been established for over a quarter of century, the term information art has been used recently to refer to various new types of works of art produced in a variety of different contexts. One use of the term refers to the commercial art or craft of designing interactive documents (e.g., Web pages) and, in general, interactive systems as the curricula of one university department suggests. ${ }^{1}$ This particular usage, which refers to the craft of information and interaction design, is excluded from the discussion here. Instead, the article deals with nonutilitarian works of art that use information as their primary medium of expression ${ }^{2}$ instead of the traditional media of paint and charcoal or stone and bronze. To articulate the specific meaning of the term referred to in this article, it is necessary to have a brief look at earlier examples of artworks that combine art with science and technology.

\footnotetext{
${ }^{1}$ School of Information Arts and Technologies, University of Baltimore (http://iat.ubalt.edu/index.htm)

${ }^{2}$ This statement is slightly misleading and certainly requires elaboration; however, the reader should read it metaphorically at this stage. Its meaning will become clear later in the article.
} 
The earliest experiments with information technology in arts involved computer-generated images. One of the pioneers in this field was A. Michael Noll, who generated in 1960s images that look uncannily like Mondrian paintings with the help of (by today's standards) simple computer graphics technology then available. There were other contemporaries such as Charles Csuri, who was similarly producing primitive computer-generated images that could be considered as first examples of computer-aided art (Gere, 2002). Early experiments in computer graphics and related experiments in computer music could be seen as attempts to explicitly use high technology in the creation of art. There was, however, another kind of experimental art produced in the 1960s and early 1970s, which did not always use computers or other high-tech tools but was inspired or influenced by technological ideas and scientific concepts of the period. Shanken (2002) referred to these experiments as "art-and-technology:"

Art-and-technology has focused its inquiry on the materials and/or concepts of technology and science, which it recognizes artists have historically incorporated in their work. Its investigations include: (1) the aesthetic examination of the visual forms of science and technology, (2) the application of science and technology in order to create visual forms and (3) the use of scientific concepts and technological media both to question their prescribed applications and to create new aesthetic models. (p. 434)

The following are some examples from the period that illustrates the aforementioned points. News and Visitor's Profile are two works created by the conceptual artist Hans Haacke, which were shown in the Software, Information Technology: Its New Meaning for Art exhibition curated by art critic Jack Burnham, held in 1970 in New York. The first work consisted of several Teletype machines that printed out on continuous rolls of paper news about national and international events in real time. Visitor's Profile was a computerized system that cross-tabulated demographic information about exhibition visitors with their opinions on a variety of topics (Shanken, 2002). Both works were influenced by Cybernetics and related technoscientific discourse of the era. Contact: A Cybernetic Sculpture (1969) by Les Levine involved video cameras that captured images of viewers which were fed back with time delay and other types of distortions to a number of monitors (Shanken, 2002). This work, like many others from the same period, also was influenced by ideas from Cybernetics and interactive information technology. Cybernetics, General Systems Theory, and Information (Communication) Theory of Shannon and Weaver (1949) were indeed the dominant scientific discourses of the 1950s and 1960s, and many artists of the time explicitly or implicitly drew inspiration and ideas from them (Gere, 2002). The curator of the Software exhibition, Burnham, in a number of essays explicitly drew comparisons between computer software and ideas/concepts that underlie art objects, which were in turn compared to hardware (Shanken, 2002). Another work by Levine, System's Burn-Off X Residual Software (1969), which documented "the media spectacle" was comprised of 1,000 copies of 31 photographs taken by Levine at the opening of the highly publicized Earth Works (1969) exhibition in New York. The work was exhibited in the Software exhibition. Although Systems Burn-Off did not incorporate any high-tech equipment, the ideas behind it drew from Cybernetics and information technology. As Shanken (2002) explained:

System's Burn-Off was an artwork that produced information (software) about the information produced and disseminated by the media (software) about art (hardware). It offered a critique of the systemic process through which art objects (hardware) become transformed by the media into information about art objects (software). (p. 434)

These experiments, which mixed art with scientific discourse and technology, should be understood in relation to parallel developments in art in the 1960s. Conceptual art, sometimes called "concept art" or "idea art," was the leading art movement of the era and left indelible marks on the artworks created ever since. Its influence is still being felt strongly in the contemporary art scene (Wood, 2002, pp. 8-9). There were strong similarities between the ideas behind the works of conceptual artists and those who were involved in art-and-technology experiments of the 1960s (Shanken, 2002). As noted earlier, Haacke, who was one of the leading figures in art-and-technology experiments, also was a prominent figure in the conceptual art movement. Conceptual art was interested in analyzing the ideas underlying the creation and reception of art. It de-emphasized the value traditionally accorded to the materiality of art objects and focused on examining the preconditions of how meaning emerges in art, which is seen as a semiotic system (Shanken, 2002, p. 434). For this reason, it is seen as a movement that merges art with philosophy (Alberro, 2003; Wood, 2002). In the words of art critic and curator Burnham (1970/2000):

Beyond a fundamental re-evaluation of the meaning of art, Conceptualism inadvertently asks, "What is the nature of ideas? How are they disseminated and transformed? And how do we free ourselves of the confusion between ideas and their correlations with physical reality?" (p. 217)

In short, the dictum of Conceptual art was "art as idea." The art object is no longer materially but conceptually defined. Art becomes a matter of opinion, and its importance is located almost exclusively in its meaning (Alberro, 2003). Conceptual artists eschewed use of traditional materials such as paint or charcoal in their works. The key issue for them was the separation of art (idea) from its material presentation and the preferred media for conceptual art were usually language and graphics. It is notable in this context that conceptual artists and theorists talked about "primary information" (i.e., the essence of the piece, its ideational part) and "secondary information" (i.e., the material information by which one becomes aware of the piece, the form of presentation).

In the context of the previous discussion, one possible meaning of the term information art can be identified. Although the 
term information art was not used by conceptual artists or the related group of artists engaged in art-and-technology experiments discussed earlier, clearly such work emphasized the "meaning" and "ideational content" of art over its physical manifestation. Such work was therefore primarily not made for looking at but for mentally engaging or informing the viewer. Indeed, several pieces from the period contained or sometimes entirely consisted of linguistic definitions, collection of facts and statements, instructions to be followed by the viewer, and images taken from mass media. One of the contemporary conceptual artists, Malloy (as cited in Topping, 2000), stated that:

Information art is a kind of conceptual art that is based on collections of information that convey some meaning as a whole and are (usually) deliberately assembled by artists for this purpose. It could be collections of statements-such as Hans Haacke's On Social Grease (1975) that is based on (mostly corporate) remarks about art; or, images from the mass media such as the collection Hal Fischer made in the early 80's of advertising from the Poppers industry or Peter D'Agostino's 1981 collections of telecommunications ads Invading The Information Age. [formatting modified]

However, information content is not the only defining characteristic of art-and-technology experiments and conceptual artworks of the 1960s. There is another aspect of them which is more relevant to the discussion of contemporary works of information art discussed in the next section. Both types of art were self-reflexive and meta-critical. Conceptual art of the period challenged the limits and problematized the meaning of art and the function of the artist. It conceived artist as a social and political critic rather than as a craftsman, and art as a process of interrogation of the structures of knowledge and systems of signification that made "possible art to produce meaning in art's multiple contexts, including its history and criticism, exhibitions and markets" (Shanken, 2002, p. 434). Similarly, art-and-technology experiments were interested in the social and aesthetic implications of technological media that define, package, and distribute information and the systems of knowledge that structure scientific methods and conventional aesthetic values (Shanken, 2002, p. 434). It is in this context that the type of art exemplified earlier in this section should be seen as predecessor to the new breed of high-tech or information arts that are discussed in the next section. The defining characteristic of the new breed of information arts is that such works help answer or generate significant questions regarding fundamental epistemological and ontological assumptions relevant to the scientific disciplines from which the artwork derives its methods, concepts, or tools. ${ }^{3}$ In the

\footnotetext{
${ }^{3}$ It is questionable whether this kind of art should still be called "information art" or, for instance, "knowledge art," echoing the arguments that whether "information science" is an accurate label to refer to the type of activities carried under this name. Further discussion of this point will not be dealt with until later in the article. It is worth noting here that the choice of the name is fortune in that it signals a possible similarity of content between information science and information arts, which is the main thesis of this article.
}

1960s, conceptual art and related experimentation with technology were influenced by the dominant technoscientific discourse of that period. The questions these artworks raised were, in general, limited to Cybernetics and related discourses of Systems Science and Information (Communication) Theory. As it will be shown in the next section, this has changed dramatically in the last decade, and many more scientific disciplines have been referenced and more complex questions raised.

\section{New Conceptual Information Arts}

Shortly after the Software exhibition in 1970, the cybernetic era was over-no major art gallery in Britain and the United States exhibited such work for more than 30 years (Gere, 2002). Conceptual art has continued to be a major influence in the contemporary art scene right to the present day, although few artists today explicitly identify themselves with the 1960s' conceptual movement. Reasons for the parting of ways between the art world and cyberneticsinfluenced 1960s' experimental art include (a) technical failures in art-and-technology exhibitions, (b) skepticism toward materiality and spectacle of mechanical apparatuses and modernist object, (c) skepticism toward the firstorder cybernetics' military-industrial connections and connotations, and (d) the fact that many technological innovations pioneered in such work have been progressively integrated to off-the-shelf consumer products (Gere, 2002; Shanken, 2002). Some artists did continue to use Cybernetic/Systems concepts throughout the 1970s and 1980s, but interest shifted from automation, control, and feedback to body and the subjective human observer which paralleled the developments in the second-order cybernetics (Gere, 2002).

Recently, there has been a renewed interest in the relationships between art, science, and technology. Stephen Wilson's (2002) compendium entitled "Information Arts: Intersections of Art, Science, and Technology" testifies this turn in fortunes. The volume, which features over 1,000 artists in some 900 pages, is a survey of works created mainly within the last decade that integrate art with science and technology. Although the works surveyed in this volume have clear relationships to the type of art described in the preceding section, there are major differences that need to be underlined. Body and subjectivity seem to continue to play an important part in many of the surveyed works of art; however, there are many more diverse themes that these works of art address. The most significant difference is that use of scientific concepts and ideas is no longer limited to Cybernetics, Systems Science, Information/Communication Theory, and related discourses. Many other scientific disciplines directly contributed to the works surveyed in this compendium. The book is organized according to scientific fields referenced by the surveyed works, which reveals the diversity of disciplines that contributed to the creation of works of art. The following are the main divisions of the book. The surveyed 
artists and artworks are discussed under one or more of these categories:

- Biology: Microbiology, Genetic Engineering; Animals and Plants; Ecology; Medicine and Body.

- Physical Sciences: Physics; Chemistry; Geology; Geographic Positioning Systems; Astronomy; Space Science; Atomic Physics; Nuclear Science; Nanotechnology; Nonlinear Systems.

- Algorithms and Mathematics: Algorithmic Art; Artificial Life; Fractals; Genetic, Evolutionary and Organic Art.

- Kinetics, Sound Installations, and Robots: Robotics and Kinetics; Kinetic Instruments; Sound Sculpture and Industrial Music.

- Telecommunications: Telephone; Radio; Net.Radio; Teleconferencing; Videoconferencing; Satellites; the Internet; Telepresence; Web Art.

- Digital Information Systems/Computers: Interactive Media; Virtual Reality; Motion, Touch, Gaze Sensors; Artificial Intelligence; 3-D Sound; Speech Synthesis; Scientific Visualization; Information and Surveillance.

The main thesis of Stephen Wilson's (2002) Information Arts is that the meaning and character of science- and technology-oriented art have been dramatically changing since the beginning of the 1990s. The artists who have experimented with science and technology in recent years do not see art as a practice of creating merely aesthetic objects or social commentary, according to Wilson (2002). Instead, art has become a kind of research.

\section{Art as Research}

As discussed in the preceding section, early conceptual art and art-and-technology experiments can be considered works of information art in a particular sense: They carry messages that express ideas and opinions. In some cases, the works specifically consisted of information collected and assembled from various sources that comment or inform on various social and cultural issues. As Deleuze and Guattari (1994) stated, in conceptual art: “. . . the plan of composition tends to become 'informative' and the sensation depends upon the simple 'opinion' of spectator who determines whether or not to 'materialize' the sensation, that is to say, decides whether or not it is art" (p. 198). A special interest was paid to the use of language and, more generally, signs in conveying messages/information and the complicated relationships between art and new information and telecommunications technologies that are used in the production and dissemination of artworks.

Wilson (2002) used the label "Information Arts" in his aforementioned book in a broader sense, however. Wilson's (2002) Information Arts charts the changing role of the artist and the character of artworks that have been created within the last decade. Art, science, and technology always have had close relationships, but the relationship of art to science and technology is rapidly changing in an era dominated by technological and scientific research, and the artists are responding to these changes by becoming a new kind of re- searcher, according to Wilson (2002). Artists are developing various strategies in response to changes in the social and cultural domains. As Wilson (2004a) stated:

Many artists are becoming active in research areas but the approaches they take vary widely. One response positions artists as consumers of the new tools, using them to create new images, sounds, video, and events; another response sees artists emphasizing the critical functions of art to comment on the developments from the distance; a final approach urges artists to enter into the heart of research as core participants, developing their own research agendas and undertaking their own investigations.

The character of this new kind of research is discussed in detail in the next section. It is suffice to reiterate here the similarities between art-and-technology experiments and conceptual art of 1960s and the new types of works of art described in Wilson's (2002) book. Both kinds of art are interested in interrogating the social structures and systems of knowledge and signification that shape conventional aesthetic values as well as scientific methods. It is in this context that early conceptual information art and the new breed of high-tech art surveyed in Wilson's book and discussed next are related. More specifically, it is one of the main theses of this article that conceptual information arts have moved from its beginnings as experiments that challenged the limits and meaning of art and cybernetics-related discourses in the 1960s to a highly sophisticated research-like work that produces new knowledge relevant to many diverse scientific disciplines by answering or generating significant epistemological and ontological questions or creating new knowledge, tools and procedures. There are many documented examples of such work, a few of which are discussed in the next section. ${ }^{4}$

\section{From Ideas to Knowledge Production (Research)}

The new breed of artists contributes to science in a variety of ways. The works of art they produce may require invention of new tools or devices, which might be useful for scientific research as well. The work of art itself may inspire scientists to see in a new light or think differently about fundamental principles or methods in their fields. Alternatively, the work of art may be a direct source of information or knowledge ${ }^{5}$ that enhances scientific thinking and research. Wilson (2004a) elaborated on the ways artists could contribute to science:

Artists might assign different priorities to various research agendas.

Artists might ask different research questions.

Artists might help deconstruct unacknowledged assumptions in the frameworks that guide research.

\footnotetext{
${ }^{4}$ The examples are mainly from Wilson, as he is one of the few researchers/artists working in this emerging field who provides detailed accounts of works of information art. Other detailed accounts can be found in Ede (2005) and in Arends and Thackara (2003).

${ }^{5}$ It will not be attempted to differentiate between these terms until the Information Science and Art section later in this article (also see Footnote 3).
} 
Artists might challenge standard research procedures or invent new ones.

Artists might discover new knowledge or invent new technologies.

Artists might interpret results differently.

Artists might invent new ways to extract understanding via information visualization.

Artists might identify cultural implications of research results missed by other researchers.

One current area of intense artistic activity is bioarts. Three examples from bioarts ${ }^{6}$ and another example related to information retrieval (IR) are discussed in this section to illustrate some of the possible ways of integrating art and science. The first work that will be discussed is an example of how artists could help invent new tools. Paul Vanouse is an artist whose work relates to genetics. His work Relative Velocity Inscription Device (2002) is mainly a social commentary on race, gender, and related issues. For this work, Vanouse extracted DNA samples from members of different racial groups and subjected them to electrophoresis (Wilson, 2004a). Electrophoresis is a method used in molecular biology to separate proteins, nucleic acids, and other subcellular particles. It is based on the principle that biological samples subjected to electrostatic field separate and migrate at different rates depending on their surface net charge density (Tietz, 2005). Vanouse in this work created a metaphoric athletics spectacle in which DNA samples from different racial groups are watched to compete. The work required a larger and quicker than standard electrophoresis equipment. This technical requirement forced the artist to design and construct a new type of electrophoresis device. The artist thus functioned as technological innovator and invented a device that may one day prove to be useful in scientific research (Wilson, 2004a).

The second example shows how bioarts research could contribute to radical new ways of thinking in science. In his 1990 work Microvenus, Joe Davis digitized and translated into a string of 28 DNA nucleotides a figure based on Germanic rune representing the female Earth. The genetically engineered DNA sequences that carry the graphical message were then inserted into the genomes of living E. coli bacteria. Davis called this work an "infogene." Fifteen years ago, Davis's idea of using DNA to encode extrabiological information, not just genetic sequences, was novel and did not have many precedents. Today, computer scientists and genetic engineers are working on DNA computing techniques and biological computers that could revolutionize computer science in the not-too-distant future (Gibbs, 2001; Wilson 2004a). We do not know whether any of the pioneers of the DNA computing had any familiarity with Davis's work, and if they had, whether they drew any inspiration or knowledge from it; however, it is plausible to imagine that any scientist with relevant background and preparedness could have been inspired by this work if he or she had come in contact with it. Although the artistic motivation behind it is most certainly different, the importance of this work is that it has the potential to inform or inspire those with relevant background and preparedness to think radically about fundamentals of computer science. Therefore, it illustrates how artistic creativity could be a source of potential inspiration and perhaps knowledge, and could have significant consequences for scientific research.

The third work is again from bioarts. SymbioticA is a research laboratory dedicated to the artistic exploration of scientific knowledge and biological technologies within the School of Anatomy \& Human Biology at the University of Western Australia. The Web site for the $1 a b^{7}$ states that:

SymbioticA is the first research laboratory of its kind, in that it enables artists to engage in wet biology practices in a biological science department. Developments in science and technology, in particular in the life sciences, are having a profound effect on society, its values, belief systems and treatment of individuals, groups and the environment. The interaction of art, science, industry and society is recognized internationally as an essential avenue for innovation and invention, and as a way to explore, envision and critique possible futures. Science and Art both attempt to explain the world around us in ways that are profoundly different but which can be complementary to each other.

Artists can act as important catalysts for creative and innovative processes and outcomes. They also can critically examine the various assumptions, and sometimes selfdelusions, built in to the "scientific method." There is a need for artists and other nonscientists to actively participate in research into possible and contestable futures arising from the application of newly acquired knowledge. While nonscientifically trained artists may have a limited ability to analyze the detailed veracity of scientific work, "outsiders" working in a different mental framework can bring both insights and distractions into the debates about the mechanisms, ethics, and philosophy behind scientific work. This can be effective only if those same artists engage actively in the science and the debate so that they have enough understanding of the process and work to engage meaningfully with it.

SymbioticA sets out to provide a situation where this can happen, an opportunity in which interdisciplinary research and other knowledge and concept-generating activities can take place. It provides an opportunity for researchers to pursue curiosity-based explorations free of the demands and constraints associated with the current culture of scientific research. SymbioticA also offers a new means of artistic inquiry, one in which artists actively use the tools and technologies of science not just to comment about them but also to explore their possibilities.

One of the SymbioticA projects is called "Bioreactor." ${ }^{\text {" The }}$ aim of the project is to create "semiliving sculptures/ objects" from living tissues that can be grown, sustained, and displayed

\footnotetext{
${ }^{7}$ http://www.symbiotica.uwa.edu.au/info/info.html

${ }^{8}$ http://www.symbiotica.uwa.edu.au/research/bioreactor.html
} 
in nonspecialized environments (e.g., museums). The work requires the SymbioticA team to tackle complex scientific challenges addressed only by researchers working at the cutting edge of biosciences. As Wilson (2004a) explained:

For example, they had to figure out ways to provide nourishment to growing cells and new ways of providing lattices to guide growth in the patterns they wanted. These investigations are another example of artists undertaking work that typically would be conducted by engineers or scientists in more conventional settings. The artistic agenda demanded they develop unorthodox skills and understandings necessary to complete the work. In doing so, they potentially add to the knowledge in this emerging field similarly to the way other researchers might.

The last example is a work by Stephen Wilson and concerns IR. In Traces of Culture (Wilson, 2004b, 2005), which was exhibited at the ACM Multimedia conference in 2004, users are invited to participate in a number of "events" organized around the theme of Web search engines and multimedia retrieval. It exists both as a gallery installation and as a Web site. In one of the events, called "Search Matrix," users are presented with lists of query terms from a variety of search engines on the Web. Clicking on a word brings up thumbnail-size images retrieved by it, which are animated and displayed in a variety of forms on the screen, creating a "collage." In another event, the user can view the past search terms submitted to the system by other users through the Web site and images retrieved by them. In "Cinema of $\mathrm{Fa}$ mous Texts," the user is presented with images that represent books by famous authors. Clicking on one of the images displays the text of the book in a scrolling line. Clicking on one of the animated words from the book displays images associated with it. Traces of Culture probes into the search process and investigates questions of meaning, ambiguity, and element of surprise that underlie it in humorous and visually interesting ways. In Wilson's (2005) words:

Traces of Culture presents a series of real time interactive art events that investigate [the] search process and the underlying compendium. It reflects on:

- The nature of search (sometimes yielding what was expected and sometimes presenting surprises-either less or more than was anticipated)

- The relationship between words and images

- The richness and diversity of the world's images stored on the Web

- Our assumptions about what is on the Web and how it can be accessed

As the previous examples described, this work provides a rich, artistic environment that could inspire and help tap into intuitive, preverbal, creative thought processes. In the next section, the ways in which artistic research could contribute to scientific knowledge are discussed in the context of evaluation of new forms of hybrid art-science-technology experiments, called information arts.

\section{Work of Art as Research Document}

Arguably, the art world is in crisis. Ivan Massow, then chairman of the Institute of Contemporary Arts (ICA), the premier platform for contemporary arts in Britain, reportedly remarked in 2002 that most concept art is "pretentious, selfindulgent, craftless tat" (Gibbons, 2002). In fact "the end of art" has been proclaimed by several critics/theorists in the last decades for different reasons (Doorman, 2003). One such critic is philosopher Arthur Danto, who in After the End of Art (1997) stated that:

To say that history is over is to say that there is no longer a pale of history for works of art to fall outside of. Everything is possible. Anything can be art. And, because the present situation is essentially unstructured, one can no longer fit a master narrative to it [emphasis added]. (p. 114)

This fact is well known to the conceptual artists of the 1960s. Indeed, one of the pioneers of the 1960s' conceptual art movement, Joseph Kosuth (1969/2000), wrote (quoting Donald Judd, another pioneer from the same period): "If someone calls it art it's art" (p. 163). The apparent lack of rules is arguably at the root of the crisis in contemporary art echoed by the former chairman of the ICA. How to evaluate modern art, thus, has become problematic. In this and the following section, an approach to evaluation of new forms of high-tech art is presented, which is hoped to provide us with a more "objective" framework for the assessment of the value of certain kinds of works of art. Furthermore, this approach will help us relate the emerging field of information arts to information science in the Information Science and Art section later in this article.

To arrive at an evaluation framework for the new forms of art and science experiments, we first look at how an information artist does research in more detail. Wilson (1995), in Artificial Intelligence as Research, describes the learning process he went through to become familiar with the important research issues in Artificial Intelligence (AI):

I undertook to learn what I could about the research agendas, accomplishments, and unresolved problems of the field. I read extensively, took courses, dived into LISP, ${ }^{9}$ attended meetings, and corresponded with researchers. I identified areas of research that seemed undeveloped and entertained questions derived from this contact with the field. I produced art installations that focused on issues in artificial intelligence research.

Wilson (1995), then, exemplified some of the dominant AI assumptions he had questioned from the perspective of an artist concerned with nontechnical, cultural, and aesthetic aspects of AI programs and systems:

Some discourse about AI seems to imply that intelligence can be viewed as an abstract, disembodied process. This view assumes that there is a "correct" way for the processes

\footnotetext{
${ }^{9} \mathrm{~A}$ functional programming language favored by artificial intelligence researchers.
} 
of natural language understanding, planning, problem solving, or vision to function and that there are "raw" meanings that programs can understand and manipulate. In this view, understanding and problem solving are technical accomplishments that can be assessed objectively.

In interactions with AI programs, technical correctness in response is often viewed as the only criterion to evaluate interaction. Correctness means that the human interactor judges that the program's response indicates that it understood the gist of the human's communication. Except in extremely circumscribed contexts, this restricted interaction may be unacceptable: humans crave texture in interactions with intelligent entities that go beyond technical correctness-for example, personality, mood, purposiveness, sensitivity, fallibility, humor, style, emotion, self-awareness, growth, and moral and aesthetic values. Disaffection with limited interactions will become more severe as AI applications spread. ... AI researchers who believe they are objectively avoiding these issues may be deluding themselves. Similarly, those who believe they are only following the classic scientific strategy of defining manageable research problems are underestimating the nature of what is being defined away.

This detailed account of an information artist's research into AI exemplifies the type of contribution that could be expected from artists working with technology, concepts, and methods/techniques borrowed from science today. Comparison of the examples of works of art given in the Early Conceptual Information Arts section with those discussed in the From Ideas to Knowledge Production (Research) section and the present section makes it possible to substantiate the main claim of the article so far: Conceptual art of the 1960s that dealt mainly with (simple) ideas mutated into a complex activity that deals with important research questions. In other words, "idea art" of the 1960s transformed into a sophisticated from of "information art" in the 1990s, which takes part in knowledge production in various ways. In this transformation, a shift from work of art as representation of ideas or opinions to work of art as representation of fully worked-out research problems can be observed. This is a shift from "art as concept" to "art as fully developed research document." It could therefore be concluded that whereas earlier conceptual works of art informed the spectator about the ideas and opinions of their creators, the contemporary works of information art inform about problems pertinent to scientific and technological issues. A work of art has become, in this new period, a document that communicates technological and scientific information. ${ }^{10}$

\footnotetext{
${ }^{10}$ It could be argued that art always involves research, and documenting it is important to many forms of art, especially to conceptually oriented art; however, in the new kind of art described here, research undertaken is usually deeper, more technical and systematic, involves going through a learning process similar to scientific training, and more often than not, its content comprises specifically scientific material. Perhaps we could simply say that the new type of art discussed here practices a more disciplined inquiry, in the sense used by Guba (1990), compared to other types of art.
}

Therefore, the purpose or function of a work of information art can be formulated as:

The purpose or function of a work of information art is to facilitate communication of pertinent scientific and technological information. ${ }^{11}$

In a more open form:

Information art helps generate or answer significant questions regarding fundamental epistemological and ontological assumptions relevant to the scientific discipline(s) from which the work derives its methods, concepts, or tools.

This definition enables us to make the following statement regarding the value of a work of information art:

(V) Value of a work of information art is related to its potential to inform or address pertinent research questions/ problems.

This statement echoes directly the approach proposed by Hjørland (1992) to subject analysis of (scientific) documents, and will enable us to relate information arts to information science in the Information Science and Art section later in this article.

\section{Axiology}

Axiology is a branch of philosophy that studies the nature of values and value judgments, including those of both aesthetics and ethics (Kemerling, 2002). It is derived from "axios" (of like value, worthy) and "logos" (account, reason, theory) (Runes, 1942). Based on the earlier statement (V) regarding the value of art, Figure 1 suggests that there are different levels at which the value of a work of art could be evaluated. At a more superficial or pragmatic level, a work of art might pose question(s) or inspire new ideas that are valid in a field of inquiry regardless of various different approaches, frameworks, schools of thought, or paradigms that may exist in that field; however, it is well known that in any scientific discipline, or more generally, disciplined inquiry, there are many different research agendas and approaches to the object of study that determine the types of questions asked and prescribe ways of going about answering those questions. Research is conducted within a theoretical and methodological framework, which "determines what questions are legitimate, how answers may be obtained, what are counted as facts and what significance is attached to these facts" (Burgess-Limerick, Abernethy, \& Limerick, 1994, p. 139). Thus, philosophers and sociologists of science talk about "paradigms" in a given field of study. The concept of paradigm is usually associated with Kuhn's work on the progress in science (as cited in Skrtic, 1990). Kuhn's (1962) use of the term is neither consistent nor clear (Ellis, 1992; Skrtic, 1990). Later, Masterman (1970) identified 21 senses

\footnotetext{
${ }^{11}$ This formulation is akin to the definition of the function of art given by Iseminger (2004) from a perspective known as aestheticism: "The function of the artworld and practice of art is to promote aesthetic communication" (p. 23). The discussion of the similarities and differences between the two definitions, however, is beyond the scope of the present article.
} 


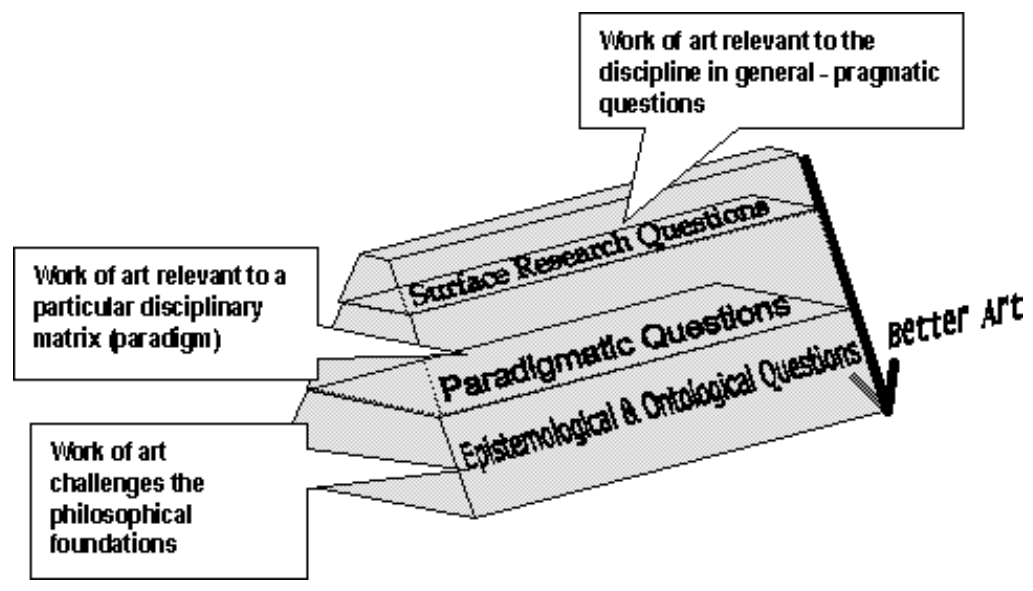

FIG. 1. The axiological framework for information arts.

of the term, which could be categorized under three main headings (Ellis, 1992, p. 46): (a) metaphysical paradigms, (b) sociological paradigms, and (c) artifact or construct paradigms.

Of the three categories, the metaphysical or meta-theoretical paradigm is more fundamental ${ }^{12}$ in the sense that it determines the sociological and the artifact/construct paradigms (Skrtic, 1990). The metaphysical or meta-theoretical paradigm is the broadest unit of consensus or a total world view (Weltanschauung) in a given science. The sociological paradigm is a concrete set of habits or a universally accepted scientific achievement. Artifact paradigms refer to specific tools, instruments, and procedures of collecting data (Skrtic, 1990). Ellis, on the other hand, suggested that the artifact paradigm is defined by exemplary past achievements or exemplars that provide "a way of seeing a problem as being like another" (Ellis, 1992, p. 48). It seems that there is an overlap between the definitions of the sociological and artifact paradigms given by Skrtic and Ellis; however, for our purpose, it is sufficient here to distinguish between $a$ set of philosophical assumptions that underpin research approaches or theories in a field of inquiry. In this article, the term "paradigm" is used to refer to particular approaches or theories in scientific research, or more generally, other types of disciplined inquiry, underpinned by a set of metaphysical assumptions. The latter is characterized in terms of the following three types of basic questions (Guba, 1990):

- Ontological: What is the nature of the "knowable?" Or, what is the nature of "reality?"

- Epistemological: What is the nature of the relationship between the knower (the inquirer) and the known (or knowable)?

- Methodological: How should the inquirer go about finding out knowledge? (p. 18)

\footnotetext{
${ }^{12}$ Ellis (1992, pp. 46-47), on the other hand, stated that according to Masterman artefact or construct paradigm is more fundamental in the sense that it precedes the other two kinds of paradigms. From our perspective, it is not important which paradigm precedes the others, but once a set of metatheoretical (metaphysical) assumptions are established in a field of inquiry, it tends to determine the type of questions asked and how research is conducted in that field.
}

Lincoln (1990) identified three competing contemporary paradigms (or meta-theories ${ }^{13}$ ) in social sciences: Postpositivist, Critical Theory, and Constructivist. The underpinning metaphysical assumptions of these are summarized in Table 1, taken from Lincoln (p. 78).

Ellis (1992) identified two major paradigms in IR research: physical or archetypal and cognitive. The archetypal paradigm has origins in the Cranfield tests, which established the principle that relative merits of retrieval systems had to be empirically determined. This approach focuses on the systems, algorithm, and representations of knowledge recorded in physical media (Ellis, 1992), and can be seen as a case of empiricism with a strong objectivist bent. Cognitive paradigm, on the other hand, was developed in the 1970s and 1980s in reaction to the archetypal paradigm. It assumes all information processing is mediated by a system of categories of concepts which are a model of the world (Ellis, 1992). This paradigm focuses on the individual user and his or her mental models, knowledge-structures, and can be considered as a case of rationalism with a strong subjective idealist bent (methodological individualism) (Hjørland, 1997b). Hjørland's (1992, 1997a; Hjørland \& Albrechtsen, 1995) work represents a more recent approach to information seeking and subject analysis in information science. This approach is sometimes called sociocognitive (Hjørland, 2002) and focuses on discourse communities, disciplines, division of labor in society, and institutional practices. Cognitive structures in this approach are seen as social and historical rather than as individual. This paradigm is related to the activity theory of Vygotsky (1978) in psychology and more generally to social-constructivist meta-theory and critical realism.

It is possible to find studies that explicate philosophical bases of theories in other disciplines as well. King and

\footnotetext{
${ }^{13}$ These are meta-theories rather than theories in the sense that they are general, higher order, or fundamental "big" theories which underlie the approach of a whole scientific tradition and are not empirically testable. Examples in social sciences include utilitarian theory, Marxism, behaviorist psychology, symbolic interactionism, Durkheimian sociology, Weberian sociology, and structural functionalism. Meta-theories can generate (specific) theories that are potentially testable (Roberts, 1999).
} 
TABLE 1. Contrasts between the Postpositivist, Critical Theory, and Constructivist Paradigms.

\begin{tabular}{llll}
\hline & & \multicolumn{2}{c}{ Paradigm } \\
\cline { 2 - 4 } Question & \multicolumn{1}{c}{ Postpositivist } & Critical theory & Constructivist \\
\hline Ontology & Realist & Realist & Relativist \\
Epistemology & Dualist, objectivist & Interactive, subjectivist & Interactive, subjectivist \\
Methodology & Interventionist & Participative & Hermeneutic, dialectic \\
\hline
\end{tabular}

Kimble (2004) identified philosophical underpinnings of various approaches to software engineering. Table 2 summarizes their findings. Burgess-Limerick et al. (1994), in a similar vein, analyzed the philosophical bases of representational and nonrepresentational approaches to understanding the control of movement in experimental psychology. Although the accuracy and validity of the analyses of philosophical underpinnings of theoretical approaches from different disciplines cited earlier are debatable, it is hoped that they illustrate the claim that all research is conducted within a theoretical and methodological framework underpinned by usually implicit assumptions about the nature of reality and ways of accessing it.

Statement $(\mathrm{V})$ about the value of works of art and Figure 1 should, therefore, be read in terms of the earlier discussion about the paradigms and philosophical assumptions that underlie them. Based on the aforementioned arguments, it could be expected that a work of art could be relevant to a field of disciplined inquiry (or a number of them) in general (regardless of various paradigms that may exist), or to a particular paradigm (or paradigms) in a discipline, or at a deeper level to particular epistemological, ontological, and methodological assumptions that underlie one or more paradigms or theories. In the next section, this idea is applied schematically to a fictitious work of information art for the purpose of illustration.

\section{Evaluation of a Fictitious Work of Information Art}

It is impossible within the scope of this article to do an extensive analysis of a real work of art in terms of the axiological framework proposed in the previous section. Here, only a schematic analysis of a fictive work of art will be presented for the sake of illustration of the previously mentioned ideas. However, given the extensive discussions earlier about the comparability of works of information art to research documents, it is plausible to expect that works of art can be analyzed in similar ways that documents are analyzed by information scientists working within the domain-analytic or sociocognitive framework. For instance, Hjørland (2002) analyzed subjects of documents in terms of the epistemological positions of various theories in psychology. Given the feasibility of such an analysis for scientific documents and the analogy between documents and works of information art, it is reasonable to expect that a similar analysis also could be conducted for real works of art.

The fictitious example that will be used as illustration is as follows: Let us assume that there is an immersive 3D interactive art installation, which represents a library where users (i.e., viewers) manipulate the books and other items on the shelves directly by hand movements without the use of a "mouse" or other traditional input devices such as a keyboard. This is possible with the currently available computer vision techniques. It is conceivable that this installation could inspire a researcher working in the field of digital libraries to imagine alternative interface designs. Although interface design for retrieval systems is a valid problem for information scientists, arguably it is not a core research area in information science. The idea of an immersive interface whereby users interact with documents with hand movements and gestures could be a useful idea for IR researchers regardless of any particular research paradigm within which they work. Thus, in terms of Figure 1, it could be said that this work of art is relevant to or has a value at the level of "Surface Research Questions" in information science.

Let us now imagine that the installation is such that queries of previous visitors (i.e., users) are recorded and visually represented as floating clouds in a 3D virtual library, which persist after the owners of the queries left the installation, and newcomers could see and manipulate them. We could imagine that an IR researcher, working from within a socially informed perspective, could be inspired by it and formulate the idea that collaboration between past and present users of IR systems could be possible and desirable. In terms

TABLE 2. Philosophical positions of software engineering methodologies.

\begin{tabular}{llll}
\hline Research strand & $\begin{array}{c}\text { Epistemological } \\
\text { position }\end{array}$ & $\begin{array}{c}\text { Ontological } \\
\text { position }\end{array}$ & Example methodologies \\
\hline Formal & Rationalist & Realist & Unity, Z, VDM \\
Semiformal & Rationalist & Anti-Realist & Jackson System Development \\
Object-oriented & Empiricist & Realist & $\begin{array}{l}\text { Booch Object Oriented Design } \\
\text { Holistic }\end{array}$ \\
\hline
\end{tabular}


of the axiological framework discussed earlier, this is a work of art relevant to socially oriented paradigm(s) in IR, such as the sociocognitive view mentioned in the previous section.

Let us now imagine that we traveled back in time 30 years or so, when the only established paradigms were the archetypal and cognitive discussed earlier. Imagine that socially informed theories did not exit at that time. It is plausible, then, to argue that the same interactive art described earlier could stimulate an IR researcher working within either the archetypal or, more likely, the cognitive paradigm to challenge the basic philosophical assumptions of that particular paradigm, for example, those related to methodological individualism. Thus, in terms of Figure 1, this is a work of the highest value, pertinent to deeper research questions in IR. Microvenus by Davis described earlier could be considered as this kind of work for computer science.

Note that it is not claimed that a work of art could easily be mapped exclusively to one of the levels of the axiological framework illustrated by Figure 1. It is more realistic to think in terms of degrees in which a work of art may be relevant to one or more of the three categories of Figure 1. Additionally, in the first example, what is considered not to be a core research question in information science, namely interface design, is a core subject in human-computer interaction, an interdisciplinary field. Therefore, a work of art that is only tangentially or superficially relevant to one discipline could be strongly relevant to another. Another note of caution is that relevance of a work of art (or a document for that matter) ultimately could be determined by researchers in a field, as its epistemological potentials are not given a priori but developed by research in that and other fields (Karamuftuoglu, 1998). The task of axiological analysis as proposed here is not simply to pass a judgment on the value of works but to uncover the often implicit assumptions that underpin them, which is in line with the approach to subject analysis proposed by Hjørland (1992, 1997a, 2002). It also is not claimed that aesthetic value of a work of art is determined exclusively or mainly by its conceptual or cognitive content. Formal and other qualities are often as important, but discussion of such aspects of art is outside the scope of the present article. Finally, as noted earlier, the examples used here are not based on a real work of art, and therefore are contrived. It is left to another study to demonstrate that the ideas outlined here could be fruitfully applied to real works of art.

\section{Information Science and Art}

To establish the relationship between information science and information art, it will be attempted to answer the following questions: What do information scientists and information artists do and how do they do it? Information artists, like other artists, create knowledge, albeit often not discursive and certainly not scientific in a narrow sense. This statement might strike as odd, as many believe that art imitates or at best represents reality. However, Doorman (2003) in a section of his book Art as Cognition, argued that conceptual content is an important part of all (even mimetic or representational) art, and art develops analogously to knowledge, not only reflecting but also creating it. Furthermore, this is a characteristic of all art: "There appears to be a similar cognitive content in different art forms - in the form of the refinement of perception, an increasing reflection and abstraction, a relativizing of cognitive categorical schemes and so on" (Doorman 2003, p. 137). Based on Goodman's (1969) epistemological symbol theory, Doorman argued that art does more than simply depicting or representing reality; it classifies and symbolizes it:

... by the delicacy of its discriminations and the aptness of its allusions; by the way it works in grasping, exploring, and informing the world; by how it analyzes, sorts, orders, and organizes; by how it participates in the making, manipulation, retention, and transformation of knowledge. (p. 140)

Obviously, cognitive content of art is based on social codes and conventions, traditions, knowledge, and discourse about the world, but at the same time creates something new and "sheds a different light on the world and contributes to knowledge of reality" (Doorman, 2003, p. 138). Art brings together the intellectual, sensual, and emotional to create a unique profusion of cognitive activities (Doorman, 2003, p. 140); but how is its intellectual content exactly different from that of science and philosophy? According to philosophers Gilles Deleuze and Félix Guattari (1994):

... from sentences or their equivalent, philosophy extracts concepts (which should not be confused with general or abstract ideas), whereas science extracts prospects (propositions that must not be confused with judgements), and art extracts percepts and affects (which must not be confused with perceptions and feelings). ${ }^{14}$ (p. 24)

According to Deleuze and Guattari (1994, p. 66), "art thinks not less than philosophy but it thinks through affects and percepts," instead of concepts as philosophy does. Art for them, therefore, is a ". . . block of sensations, that is to say, a compound of percepts and affects" (Deleuze \& Guattari, 1994, p. 164). The purpose of art, for Deleuze and Guattari (1994), is to make the imperceptible visible or perceptible:

... as music may be said to make sonorous force of time audible, in Messiaen for example, or literature, with Proust, to make the illegible force of time legible and conceivable. Is this not the definition of the percept itself-to make perceptible the imperceptible forces that populate the world, affect us, and make us become? Mondrian achieves this by simple differences between the sides of a square, Kandinsky by linear "tensions", and Kupka by planes curved around the point. [formatting modified] (p. 182)

\footnotetext{
${ }^{14}$ In the sense that they are independent of the individual creator of the work of art or the one who experiences it, as Deleuze and Guattari (1994) argued in their book. Also note that for Deleuze and Guattari, philosophical concept is different from concept understood as general or abstract idea.
} 
In information art, as defined and discussed in this article, the artist makes visible or perceptible the knowledge that science produces about the world (reality) by extracting from it, and presenting in new ways percepts and affects (sensations) that both reflect and contribute to the knowledge about the world. The creation of blocks of sensations or percepts and affects from knowledge about reality and making them visible is a transformative and creative process that generates new knowledge. Extraction of sensations is a process of decontextualization. The philosophical term for decontextualization in Deleuze and Guattari (1994) is deterritorialization. Art in Deleuze and Guattari's philosophy is an act of deterritorialization followed by an act of reterritorialization (recontextualization): "The aim of the art is to wrest the percept from perceptions of objects and the states of a perceiving subject, to wrest the affect from affections ... to extract a block of sensations ..." (p. 167). Perception of the object (i.e., the world) requires knowledge of it. We could say that without knowledge, there is no perception. ${ }^{15}$

It is in the aforementioned sense that the artist extracts sensations from the knowledge about the world. He or she frees (or deterritorializes) perception from the knowledge of the object and constructs a work of art, which is no other than blocks of percepts and affects that lead to a new perception, and therefore, knowledge about the world. In other words, the artist first decontextualizes knowledge and then recontextualizes it in a new way. Thus, art does not produce knowledge about the world directly but it organizes and transforms our knowledge of the world by making perceptible ${ }^{16}$ what is only known abstractly, in the process transforming our perception and understanding of the world, which is then picked up by scientists and others and fed back to the process of knowledge production. In the case of conceptually oriented art (including information arts), the material aspect of the work, as we have seen earlier, is often secondary to the idea (or concept) behind it. Nevertheless, the idea is organized and made visible, and thus made accessible, to a large extent by the perceptions and affections it generates on the viewer or user. Failing to do so, it remains as an abstract idea which is not fully realized and comprehended.

Artists do not acquire knowledge about the external reality to provide a systematic account of cause and effect relationships between physical bodies or allow us to develop interventions to control and manipulate variables extracted from nature like scientists. They acquire knowledge about the world to reorganize it. In other words, artists usually do not directly work with the physical reality (Popper's World 1$)^{17}$

\footnotetext{
${ }^{15}$ For a theory of perception, which is a direct source of inspiration for Deleuze and Guattari (1994), see Bergson's (1896/1911) Matter and Memory.

${ }^{16}$ Perception is always embodied, situated, and concrete; it involves a body and knowledge of the external world. Bergson (1896/1911) stated that: "It expresses and measures the power of action [italics added] in the living being, the indetermination of the movement, which will follow the receipt of the stimulus" (p. 68).

${ }^{17}$ Popper (1972).
}

like scientists but work and create in a symbolic domainproducts of the human mind (languages, myths, stories, scientific theories and mathematical constructions, songs, paintings, and sculptures, etc.; i.e., Popper's World 3) as well as the world of mental and psychological states (Popper's World 2).

How does an information artist go about acquiring knowledge about the world (Popper's World 3)? Like an information scientist, who is not a subject expert, an information artist acquires knowledge mostly from secondary and tertiary sources, and rarely from primary sources. This is one of the parallels between an information scientist and artist. The other similarity is that an information scientist, like an information artist, extracts information/knowledge from documents or other sources of knowledge; however, unlike an artist who constructs blocks of sensations, an information scientist constructs databases, abstracts, indexes, knowledge-maps, atlases of science, and other representations or secondary sources of information or knowledge. This is, of course, only a partial list of what information scientists do.

Hakken (2003) suggested that there are two opposing views of the data-information-knowledge trichotomy, which he dubbed as the modernist knowledge progression and the postmodernist knowledge regression. The modernist progression starts with data, which are conceived as raw and directly apprehensible. Data arranged or manipulated in certain ways are information. In Soft Systems thinking (Checkland, 1990), for instance, information is data plus meaning. In the modernist account, further manipulation of information according to certain procedures, such as "verification," results in knowledge (Hakken, 2003). In this view, which reflects the empiricist philosophy, the social, political, and other contexts are ignored, and therefore the progression from data to knowledge is unproblematic. The alternative postmodernist account starts with knowledge. Knowledge is seen as contextual and embodied in actual people and situations. The production of information is seen as decontextualizing or desituating knowledge, cutting it of important context. Abstracting knowledge from its context(s) is not a natural or an unproblematic process. Hence, information is inherently contrived. Data are further abstracted (deterritorialized) or "denatured" information (Hakken, 2003).

From the postmodernist perspective, documents can be seen as representations of knowledge. They do not contain knowledge as such since knowledge is embodied in situations and people. Documents contain traces or reflections of knowledge. They are part of a knowledge environment constituted by people, practices, situations, and other artifacts. A document on its own is therefore a deterritorialized representation of knowledge. From this perspective, Karamuftuoglu (1997) saw document retrieval as a process of further deterritorialization followed by reterritorialization. In this view, retrieval systems decontextualize/deterritorialize both documents and user queries further by dividing them into atomic units of keywords removed from their original contexts. This is followed 
by a matching operation, where the decontextualized keywords from queries are conjoined with similarly decontextualized keywords taken from documents. This is seen as a context control, or reterritorialization, operation.

From this perspective, creation of indexes and other secondary sources such as thesauri and knowledge maps can be seen as a process of abstracting information from primary sources (e.g., research documents). Hence, one of the main functions of an information scientist is the creation of decontextualized knowledge; that is, information. An information scientist, like the artist, works with knowledge, abstracting from it and constructing new knowledge and information ${ }^{18}$ from that abstraction in the form of thesauri, knowledge maps, indexes, abstracts, and so on; that is, relatively deterritorializing and reterritorializing knowledge. Similar to the information artist, an information scientist works in a symbolic domain of language, scientific theories, and conjectures, literature (fiction), musical information (e.g., notation), photographs, paintings, and other art. Note that reterritorialization or recontextualization always implies construction of a new context. A term reterritorialized, for instance, in a database or a thesaurus, does not have the limited meaning it has in a particular document. Similarly, it does not carry all the senses it has ever been put in use in different texts. From a structuralist point of view of language (Saussure, 1974), it can be said that a term in an index or thesaurus enters relationships with all the other terms in that representation scheme, directly or indirectly, and acquires its meanings from its associations with them. Some of these senses may be found in the published documents, and some may not yet exist (i.e., exist only potentially, waiting to be actualized in a document). On the other hand, not all senses in which it is used are likely to be captured by the thesaurus or the index.

\section{Conclusions}

We have seen that works of information art could be analyzed and evaluated in terms of paradigms (theories and meta-theories) and their epistemological, ontological, and methodological assumptions. A similar approach to subject analysis is proposed by Hjørland (1992, 1997a, 2002). Therefore, it can be suggested that the sociocognitive view developed by Hjørland is useful for both purposes, and hence can be seen as a unifying framework for the fields of information arts and information science. It was argued

\footnotetext{
${ }^{18}$ Knowledge is not a thing, as argued from the postmodernist knowledge regression position. Hence, when it is referred here and in the rest of the article to knowledge creation, it is meant the construction or creation of artifacts that are used in knowledge production processes in concrete contexts. Similarly, we use the term information to refer to artifacts used in knowledge production processes, which are relatively more decontextualized (deterritorialized) in comparison to knowledge artifacts. Therefore, the difference between knowledge and information artifacts, or knowledge and information in short, is a matter of degree of deterritorialization.
}

earlier in this article that information scientists and artists work in similar ways on three counts:

- They create new knowledge and information by abstracting from documents and other sources; that is, deterritorializing and reterritorializing knowledge.

- They work mainly in a symbolic domain, and not directly with the physical world ${ }^{19}$ in the process of acquisition and production of knowledge.

- They are not subject experts; hence, more often than not, they acquire knowledge from secondary and tertiary sources.

The first point is important and needs emphasis. Any science, or more generally, disciplined inquiry, creates new knowledge. In the case of information science, creation of new knowledge does not just mean invention of a new method of classification (e.g., faceted classification), or a search algorithm, or an approach to subject analysis, and so on. It means, more generally, production of knowledge about the world or reality through creation of secondary information sources (e.g., databases, indexes, thesauri, ontologies, knowledge maps, etc.) that organize the concepts (created by other sciences) through which we comprehend the world. Information scientists do not passively represent knowledge or transfer information from one source to another. Indexes, ontologies, databases, and other representations and sources they create make it possible for us to see new connections between concepts, and thus understand the world in new ways. The work of Swanson $(1987,1989)$ can be seen as an explicit attempt to create new knowledge by exploring logical connections between terms and concepts indexed in databases. The relational indexing scheme invented by Farradane (1970) also is based on a similar idea. However, the argument here is that knowledge creation in information science is not limited these and similar examples. The artifacts that information scientists create-in particular, the secondary sources of information-organize and transform our knowledge of the world by making certain connections between concepts and terms visible and inadvertently making others invisible. From this perspective, information science is seen as a critical science or discipline.

The critical role of artists is better understood and appreciated. Wilson (1993), for instance, wrote that:

Critical theory and cultural studies are a powerful methodology. Their perspectives are being fruitfully employed in a wide array of disciplines, including anthropology, psychiatry, politics, literature, art, media studies, and philosophy. The analyses are robust, and revolutionize the understanding of things often taken for granted.

Epistemological analyses of this sort have been fruitful when applied to the art world because it is a culture industry relatively unselfconscious about the metanarratives it assumes and the limited sets of interests it has represented.

\footnotetext{
${ }^{19}$ Although information artists sometimes conduct experiments to acquire information/knowledge directly.
} 
It is hoped that the present work would contribute to the understanding and appreciation of information science as a critical discipline and that the parallels drawn here between information science and information arts make possible unification of education in both fields. It is argued that information artists require some of the skills and knowledge of information scientists. These include, but are not limited to, knowledge about sources of information, ability to find and acquire relevant information, and learn about basic concepts in disciplines in which they do not have training. There also is a strong need for basic education in philosophy, especially philosophy of science and epistemology, in both fields. Thus, students in both fields could be educated in a common set of skills and subjects. Although, the discussion in this article is focused on scientific and technical information, it can be extended to other types of knowledge.

Finally, it might be useful to comment briefly on the label of information science. It has been suggested by a number of researchers (e.g., Capurro \& Hjørland, 2003; Hjørland, 2000) that the lack of clarity of its epistemological base makes the term information unsuitable as a label in describing the kind of activities carried out under information science. It is not possible here to discuss all the issues that surround the choice of a name for this field; however, it can be argued that the ambiguity of the concept of information makes it, on the contrary, potentially a good label. It is arguable that information science at its present state of development is a multidisciplinary field. In this respect, it might be more accurate to talk about information sciences in plural. According to Besselaar and Heimeriks (2001), multidisciplinary research uses different theoretical perspectives borrowed from various disciplines, however neither the theoretical perspectives, nor the findings of various disciplines are highly integrated. Interdisciplinary and transdisciplinary fields display a more coherent identity and integrated theoretical and methodological orientation.

The view that information science is a multidisciplinary field may seem odd. Many people think of information science as an interdisciplinary subject with a relatively established theoretical and methodological identity; however, the view here is that information science is an emerging discipline that studies production, storage, retrieval, communication, and use of information/knowledge in society. This view incorporates social and cultural as well as scientific and technological aspects of production, dissemination and use of information, and mechanisms of achieving this by computational and other means. Many disciplines have felt in the last few decades the need to address questions or face problems that do not fit in their disciplinary boundaries but are relevant to the broad domain of information science defined as the study of production, dissemination, and use of information in society. Social sciences, philosophy, linguistics and semiotics, computer science, library science and documentation, psychology, cognitive science, ergonomics, communication studies, economics, art, and management/ business studies as well as a number of "hard" sciences such as chemistry and biology have felt such a need. As a response to this need, many traditional disciplines appended information-related labels to their names: Computer and information sciences, library and information science, social/organizational/business informatics, bioinformatics, management information systems, and information arts are a few examples of such attempts of broadening disciplinary boundaries. Arguably, the emergence of the discipline of information science can be seen as a similar attempt of cross-disciplinary integration of research issues that cannot be addressed from a single disciplinary perspective. The view in this article is that information science is an emerging critical science that studies information-related phenomena at different levels, including the societal; therefore, it is important not to tie information science to a single or particular disciplinary lineage.

"Social informatics" is another label more recently proposed, ${ }^{20}$ which puts forward a similar research program. Information science is used as the preferred name here, but there is no fundamental philosophical reason for not using social informatics or any other information-related label. None of the disciplines mentioned earlier offers a sufficiently developed critical framework or broad enough scope that could adequately deal with many facets of production, communication, and use of information in society by computational and other means. The ambiguity of the concept of information helps avoid identification with a single disciplinary ancestry. This is desirable because it helps avoid premature definition and closure of the disciplinary boundaries of this developing field, and keeps open the possibility of integration of related but diverse research agendas. It must be acknowledged that the term information has been associated with positivistic connotations in the past, but as it is discussed in this article to an extent, this has been recently challenged by various critical approaches and different theoretical perspectives. It is not possible to predict at this stage how the process of delimitation of disciplinary boundaries of information science will develop and at what stage the growth of its scope will stop; however, it is important to avoid superficial unification of different disciplinary research issues by aiming integration at a deeper epistemological and methodological level. It is hoped that information science(s) will eventually develop from its present state of a multidisciplinary field into a more coherent discipline with a consistent epistemological and methodological base, and the present article is a contribution to efforts in that direction.

\footnotetext{
${ }^{20} \mathrm{See}$, for instance, the special issue of the Journal of the American Society for Information Science on social informatics (Kling, Rosenbaum, $\&$ Hert, 1998).
} 


\section{References}

Alberro, A. (2003). Conceptual art and politics of publicity. Cambridge, MA: MIT Press.

Arends, B., \& Thackara, D. (2003). Experiment: Conversations in art and science. London: The Wellcome Trust.

Bergson, J. (1911). Matter and memory. London: George Allen \& Unwin Ltd. (Original work published 1896)

Besselaar, P., van den, \& Heimeriks, G. (2001). Disciplinary, multidisciplinary, interdisciplinary: Concepts and Indicators. In M. Davis \& C. Wilson, Proceedings of 8th International Conference on Scientometrics and Informetrics, Sydney: University of New South Wales (pp. 705-716). Retrieved August 2, 2005, from http://www.niwi.knaw.nl/en/ maatschappijwetenschappen/staf/peter_s_home/new/2001issi/toonplaatje

Burgess-Limerick, R., Abernethy, B., \& Limerick, B. (1994). Identifying underlying assumptions is an integral part of research: An example from motor control. Theory \& Psychology, 4, 139-146.

Burnham, J. (2000). Alice's head: Reflections on conceptual art. In A. Alberro \& B. Stimson (Eds.), Conceptual art: A critical anthology (pp. 216-219). Cambridge, MA: MIT Press. (Original work published 1970)

Capurro, R., \& Hjørland, B. (2003). The concept of information. Annual Review of Information Science \& Technology, 37(8), 343-411.

Checkland, P. (1990). Information systems and systems thinking: Time to unite? In P. Checkland \& J. Scholes (Eds.), Soft systems methodology in action (pp. 303-315). Chichester, England: Wiley.

Danto, A. (1997). After the end of art. Contemporary art and the pale history. Princeton, NJ: Princeton University Press.

Deleuze, G., \& Guattari, F. (1994). What is philosophy? London: Verso.

Doorman, M. (2003). Art in progress. A philosophical response to the end of the avant-garde. Amsterdam: Amsterdam University Press.

Ede, S. (2005). Art \& science. London: Tauris.

Ellis, D. (1992). The physical and cognitive paradigms in information retrieval research. Journal of Documentation, 48(1), 45-64.

Farradane, J.E.L. (1970). Analysis and organization of knowledge for retrieval. Aslib Proceedings, 22, 607-616.

Gere, C. (2002). Digital culture. London: Reaktion Books.

Gibbons, F. (2002). Concept art is pretentious tat, says ICA chief. The Guardian. Retrieved August 2, 2005, from http://www.guardian.co.uk/ uk_news/story/0,3604,634797,00.html

Gibbs, W.W. (2001, April). Art as form of life. Scientific American. Retrieved August 2, 2005, from http://www.sciam.com/article.cfm? articleID=00034C05-632F-1C70-84A9809EC588EF21\&sc=I100322

Goodman, N. (1969). Languages of art: An approach to a theory of symbols. Oxford, NY: Oxford University Press.

Guba, E.G. (1990). The alternative paradigm dialog. In E.G. Guba (Ed.), The paradigm dialog (pp. 17-27). London: Sage.

Hakken D. (2003). The knowledge landscapes of cyberspace. London: Routledge.

Hjørland, B. (1992). The concept of "subject" in Information Science. Journal of Documentation, 48(2), 172-200.

Hjørland, B. (1997a). Information seeking and subject representation: An activity-theoretical approach to information science. Westport \& London: Greenwood Press.

Hjørland, B. (1997b). Information seeking knowledge organization. The presentation of a new book. Knowledge Organization, 24(3), 136-144.

Hjørland, B. (2000). Documents, memory institutions, and information science. Journal of Documentation, 56, 27-41.

Hjørland, B. (2002). Epistemology and the socio-cognitive perspective in information science. Journal of the American Society for Information Science and Technology, 53, 257-270.

Hjørland, B., \& Albrechtsen, H. (1995). Toward a new horizon in information science: Domain analysis. Journal of the American Society for Information Science, 46, 400-425.

Iseminger, G. (2004). The aesthetic function of art. Ithaca, NY: Cornell University Press.

Karamuftuoglu, M. (1997). A Deleuzoguattarian framework for understanding information systems: The case of document retrieval systems. In J.N.D. Gupta (Ed.), Proceedings of the Americas Conference on
Information Systems, Indianapolis, IN (pp. 882-884). Atlanta, GA: Association For Information Systems.

Karamuftuoglu, M. (1998). Collaborative information retrieval: Toward a social informatics view of IR Interaction. Journal of the American Society for Information Science, 49(12), 1070-1080.

Kemerling, G. (2002). Philosophy pages. Retrieved August 2, 2005, from http://www.philosophypages.com/

King, D., \& Kimble, C. (2004). Uncovering the epistemological and ontological assumptions of software designers. In Proceedings 9e colloque de l'AIM, Evry, France. Retrieved August 2, 2005, from http://www. aim2004.int-evry.fr/pdf/Aim04_King_Kimble_1.pdf

Kling, R., Rosenbaum, H., \& Hert, C. (1998). Special topic issue: Social informatics in information science. Journal of the American Society for Information Science, 49, 12.

Kosuth, J. (2000). Art after philosophy. In A. Alberro \& B. Stimson (Eds.), Conceptual art: A critical anthology (pp. 158-177). Cambridge, MA: MIT Press. (Original text published 1969).

Kuhn, T.S. (1962). The structure of scientific revolutions. Chicago: University of Chicago Press.

Lincoln, Y.S. (1990). The making of a constructivist. A remembrance of transformations past. In E.G. Guba (Ed.), The paradigm dialog (pp. 67-87). London: Sage.

Masterman, M. (1970). The nature of paradigm. In I. Lakatos \& A. Musgrave (Eds.), Criticism and growth of knowledge (pp. 59-91). Cambridge, England: Cambridge University Press.

Popper, K.R. (1972). Objective knowledge: An evolutionary approach. London: Oxford University Press.

Roberts, A. (1999). ABC of thinking. Retrieved August 2, 2005, from http://www.mdx.ac.uk/www/study/glothi.htm

Runes, D.D. (Ed.). (1942). Dictionary of philosophy. Retrieved August 2, 2005, from http://www.ditext.com/runes/index.html

Saussure, F., de. (1974). Course in general linguistics. Glasgow, Scotland: Fontana/Collins.

Shanken, E.A. (2002). Art in the information age: Technology and conceptual art. Leonardo, 35, 433-438.

Shannon, C.E., \& Weaver, W. (1949). The mathematical theory of communication. Urbana: University of Illinois.

Skrtic, T.M. (1990). Social accommodation. Toward a dialogical discourse in educational inquiry. In E.G. Guba (Ed.), The paradigm dialog (pp. 125-135). London: Sage.

Swanson, D.R. (1987). Two medical literatures that are logically but not bibliographically connected. Journal of the American Society for Information Science, 38, 228-233.

Swanson, D.R. (1989). Online search for logically-related noninteractive medical literatures: A systematic trial-and-error strategy. Journal of the American Society for Information Science, 40, 356-358.

Tietz, D. (2005). What is electrophoresis? Retrieved August 2, 2005, from http://www.his.com/ djt/elphoexplain.html

Topping, D. (2000). An aesthetic of information. Retrieved August 2, 2005, from http://ecocode.info/informationart/selectedwriting/caiia2000.shtml

Vygotsky, L.S. (1978). Mind in society: The development of higher psychological processes. Cambridge, MA: Havard University.

Wilson, S. (1993). Light and dark visions: The relationship of cultural theory to art that uses emerging technologies. Retrieved August 2, 2005, from http://userwww.sfsu.edu/ swilson/papers/postmodern.pap.html

Wilson, S. (1995). Artificial intelligence research as art. Retrieved August 2, 2005, from http://www.stanford.edu/group/SHR/4-2/text/wilson.html

Wilson, S. (2002). Information arts: Intersection of art, science, and technology. Cambridge, MA: MIT Press.

Wilson, S. (2004a). Potential contributions of Bioartists to research. Retrieved August 2, 2005, from http://userwww.sfsu.edu/\%7Eswilson/ papers/wilson.bioartschapter.html

Wilson, S. (2004b, October). Traces of culture: Searchbots scour the Web looking for visual information. In H. Schulzrinne \& N. Dimitrova (Eds.), Proceedings of the 12th annual ACM International Conference on Multimedia, New York. ACM Press.

Wilson, S. (2005). Traces of culture. Retrieved August 2, 2005, from http:// userwww.sfsu.edu/\%7Eswilson/art/traces/traces.html

Wood, P. (2002). Conceptual art. London: Tate. 